\title{
Corporate Disclosure Policy and the Informativeness of Stock Prices
}

\author{
David Gelb \\ Seton Hall University \\ and \\ Paul Zarowin \\ New York University
}

June, 2000

corresponding author: Paul Zarowin, New York University, Stern School of Business, 422 Tisch Hall, 40 West 4th Street, New York, NY 10012, Ph: 212-998-0015, Fax: 212-995-4004

email:pzarowin@stern.nyu.edu

This paper can be downloaded from the Social Science Research Network Electronic Paper Collection: http://papers.ssrn.com/paper.taf?abstract_id=235009 


\title{
Corporate Disclosure Policy and the Informativeness of Stock Prices
}

\begin{abstract}
We examine the association between voluntary corporate disclosure and the informativeness of stock prices. We measure corporate disclosure using the AIMR-FAF annual corporate disclosure ratings. We define price informativeness by the association between current stock returns and future earnings changes: more informative stock price changes contain more information about future earnings changes. To measure this association, we use the multiple regression model of Collins, Kothari, Shanken, and Sloan (1994), wherein current returns are regressed against both current and future earnings changes and future stock returns. The aggregated coefficients on the future earnings changes, which we refer to as the future ERC, is our measure of informativeness (association).

We hypothesize and find that greater disclosure is associated with greater price informativeness (i.e., higher future ERC). This is the first empirical evidence that enhanced disclosure results in stock prices that are more informative about future earnings, indicating that greater disclosure provides information benefits to the stock market.

In addition, the method we use to document the benefits of enhanced voluntary disclosure can be applied in other cases of interest to both academics and policymakers, such as assessing the benefits of additional required disclosures.
\end{abstract}




\section{Introduction}

In this paper, we examine the association between the level of voluntary corporate disclosure and the informativeness of stock prices. We measure corporate disclosure using the AIMR-FAF (Association for Investment Management Research-Financial Analysts Federation, hereafter FAF) annual corporate disclosure ratings. We define price informativeness by the association between current stock returns and future earnings changes (controlling for current earnings changes): more informative stock price changes contain more information about future earnings changes. To measure this association, we use the multiple regression model of Collins, Kothari, Shanken, and Sloan (CKSS, 1994), wherein current returns are regressed against both current and future earnings changes and future stock returns. The aggregated coefficients on the future earnings changes is our measure of infomativeness (association). We refer to this measure as the future ERC.

To implement our tests, we use a matched industry-pair design of firms ranked high vs low (top vs bottom quartile in their industry for two consecutive years) on their FAF disclosure scores. Industry matching enables us to isolate the effect of disclosure on informativeness, because it helps to control for the accounting and real business factors that affect both the inherent lead-lag relation between prices and earnings, and earnings' intrinsic variability and uncertainty (forecastability). Controlling for these factors is important, because we want to minimize the possibility that any relation we find between the level of disclosure and informativeness is due to high disclosure firms having more timely and/or forecastable earnings.

We estimate the CKSS regression for both groups (high and low disclosure), and we compare the coefficients on the future earnings changes. We expect the high disclosure group to have a significant 
positive relation between current returns and future earnings, and the low disclosure group to have little or no relation. Thus, our (alternative) hypothesis is that greater disclosure is associated with a higher future ERC (i.e., greater price informativeness), ceteris paribus. ${ }^{1}$

We are interested in assessing the benefits to the stock market of enhanced disclosure: i.e., does enhanced disclosure make stock prices more efficient signals of future earnings? Since a primary purpose of disclosure is to inform investors about (the amount, timing, and uncertainty of) future cash flows, we examine whether greater disclosure is associated with prices that are more informative about future earnings. Despite the importance of this question, there is as yet little empirical evidence to answer it. For example, as the FASB points out in SFAS No. 1, " the benefits from financial information are usually difficult or impossible to measure".

In this paper, we contribute an empirical measure of the benefits of enhanced voluntary disclosure, and perhaps more importantly, the method we use to document these benefits can be applied in other cases of interest to both academics and policymakers, such as assessing the benefits of additional required disclosures (e.g., for segments). This is valuable, because as Schipper (1995) argues, academic research has not done a very good job of informing accounting policy. Furthermore, since we test relative informativeness, our tests do not imply or require that stock prices are completely

\footnotetext{
${ }^{1}$ We also examine the incremental $\mathrm{R}^{2}$ due to the future variables, which we expect to be related to the association (since higher coefficients increase the explained variance of the dependent variable, ceteris paribus). Our primary tests are based on the coefficients, because it is infeasible to compare $\mathrm{R}^{2}$ for different samples.

We do not test the coefficient on the current earnings change. As we discuss in Section 4.1, the relation between the informativeness of disclosure and the current ERC might be positive or negative.
} 
(semi-strong form) efficient for either or both groups. This is desirable, because the Fama (1970) joint test problem precludes definitive testing of market efficiency.

By focussing on the benefits to the stock market, our research contrasts with most prior studies attempting to assess the benefits of enhanced corporate disclosure, which have focussed on benefits to the disclosing firm. Botosan (1997) and Botosan and Plumlee (1999) examine the relation between disclosure and the ex-ante cost of capital. They find that increased disclosure level and the cost of equity capital are negatively associated, as predicted by theory. Welker (1995) finds that firms with high disclosure scores have lower bid-ask spreads, a proxy for the information asymmetry component of the cost of capital, and Sengupta (1998) finds that greater disclosure is associated with lower costs of debt. Gelb (1999) also finds that information costs are lower for firms that provide more informative disclosures, based on their choice of stock repurchases as a means for one-time cash distributions. In studies dealing with changes in disclosure levels, Healy, Hutton, and Palepu (1999) find that firms increasing their disclosure lower their spreads (as well as experience additional benefits that might be the result of good current performance), and Leuz and Verrecchia (2000) find that German firms committing to a higher disclosure level experience lower bid-ask spreads and higher trading volume. However, spreads and volume are at best indirect evidence of a lower cost of capital. Rather than estimate the cost of capital or its components, we focus on how well stock returns incorporate information about future earnings.

While no other papers examine the relations among disclosure, stock prices, and future earnings, perhaps the most closely related papers to ours are Fishman and Hagerty (1989) and Lang and Lundholm (1996). By modeling how increased disclosure can lead to increased price efficiency and 
more efficient investment decisions, Fishman and Hagerty deal with benefits to both the firm and the market. Lang and Lundholm attempt to assess the benefits of disclosure in terms of informativeness for future earnings. They find that enhanced disclosure is associated with more accurate analysts' forecasts (although this result might be due to an increased analyst following). While their evidence is important, our approach measures the relation between prices and future earnings directly, rather than relying on proxies such as analyst forecasts. In addition, more accurate analysts forecasts might be evidence of firms "managing" their analyst relationships better (i.e., whisper numbers), rather than evidence of more informative prices.

We find that high disclosure firms have significantly higher future ERC's than low disclosure firms, and this result is robust to the inclusion of control variables and to variations in the length of the forecasting horizon. While our primary results are based on firms' overall disclosures as measured by the aggregate FAF scores, we also find that more extensive investor relations disclosures are most highly associated with higher future ERC's. This is the first empirical evidence that enhanced disclosure results in stock prices that are more informative about future earnings. Thus, our evidence supports the widely held belief that greater disclosure does indeed provide information benefits to the stock market.

The rest of the paper is organized as follows. Section 2 discusses our methodology. Section 3 discusses our sample and data. Section 4 discusses our empirical evidence. Section 5 concludes.

\section{Methodology}

\subsection{Regression Models}

We assess the differential informativeness of current stock prices for future earnings using the 
multiple regression model of Collins, Kothari, Shanken, and Sloan (1994), who seek to explain the low $\mathrm{R}^{2}$ 's (usually $5 \%$ to $10 \%$, Lev, 1989) from regressions of annual returns on contemporaneous annual earnings changes:

$$
R_{t}=a+b_{0} \ddot{A} E_{t}+e_{t}
$$

where the current annual earnings change, $\ddot{\mathrm{AE}} \mathrm{t}$, is scaled by either beginning of year price, $\mathrm{P}_{\mathrm{t}-1}$, or beginning earnings, $\mathrm{E}_{\mathrm{t}-1}$, and $\mathrm{b}_{0}$ is the earnings response coefficient $(\mathrm{ERC}){ }^{2} \mathrm{CKSS}$ argue that the primary reason for the low $\mathrm{R}^{2}$ 's is earnings' lack of timeliness, due to the rules of recognition and measurement of accrual accounting that cause prices in a given period to reflect information that will be reflected in earnings of future periods. This is commonly referred to the price-earnings lead-lag relation. As CKSS point out, this relation implies that equation (1) should be expanded to included future periods' (scaled) earnings changes:

$$
R_{t}=a+b_{0} \ddot{A} E_{t}+O_{\hat{o}} b_{\hat{o}} \ddot{A} E_{t+\hat{o}}+u_{t}
$$

where $\mathrm{AE}_{\mathrm{t}+\hat{o}}$ is the scaled earnings change ô periods ahead, and $\mathrm{O}_{\hat{o}} \mathrm{~b}_{\hat{o}}$ is the "future ERC". The more that the current return, $\mathrm{R}_{\mathrm{t}}$, reflects information about future earnings, the higher the future ERC is expected to be (and the higher should be the incremental $\mathrm{R}^{2}$ due to the additional regressors). Based on the results of Kothari and Sloan (1992), who show that the statistically detectable price-earnings leadlag relation is no more than three years on average, CKSS include three future years' earnings changes

\footnotetext{
${ }^{2}$ If the deflator is beginning of period earnings, the independent variable is the earnings growth rate, and it is undefined if the denominator is negative.
} 
in (2). As they predict, both the ERC rises $\left(\left[\mathrm{b}_{0}+\mathrm{O}_{\hat{o}} \mathrm{~b}_{\hat{o}}\right]\right.$ in $(2)>\mathrm{b}_{0}$ in $\left.(1)\right)$, and the regression $\mathrm{R}^{2}$ increases when the future earnings changes are included. ${ }^{3}$

CKSS point out, however, that using the actual future earnings change introduces an errors in variables problem in (2), since the theoretically correct regressor is the (unobservable) expected earnings change. This measurement error problem biases downward both the future ERC and the incremental $\mathrm{R}^{2}$ due to the future variables. In order to correct the error and eliminate the bias, an instrument is needed that is correlated with the measurement error in the independent variable, but is uncorrelated with the dependent variable. CKSS show that such an instrument is the future return, $\mathrm{R}_{t+\hat{0}}$ : since returns have little autocorrelation, $\mathrm{R}_{\mathrm{t}}$ and $\mathrm{R}_{\mathrm{t}+\hat{o}}$ are (approximately) uncorrelated at all lags, and the future return is correlated with the unexpected future earnings change (the new information during the future period), by definition. Thus, CKSS expand (2) to include future returns as additional regressors:

$$
R_{t}=a+b_{0} \ddot{A} E_{t}+O_{\hat{o}} b_{\hat{o}} \ddot{A} E_{t+\hat{o}}+O_{\hat{o}} c_{\hat{o}} R_{t+\hat{o}}+z_{t}
$$

As CKSS discuss, the hypothesized coefficients on the future returns are negative, because $\mathrm{R}_{\mathrm{t}+\hat{o}}$ is positively correlated with the measurement error in $\ddot{A E}_{t+\hat{o}}$. CKSS also estimate an expanded model that includes as instruments the earnings-price ratio, $\mathrm{E} / \mathrm{P}_{\mathrm{t}-1}$, and the contemporaneous asset growth rate,

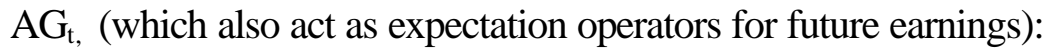

$$
\mathrm{R}_{\mathrm{t}}=\mathrm{a}+\mathrm{b}_{0} \ddot{\mathrm{A}} \mathrm{E}_{\mathrm{t}}+\mathrm{O}_{\hat{o}} \mathrm{~b}_{\hat{o}} \ddot{\mathrm{A}} \mathrm{E}_{\mathrm{t}+\hat{o}}+\mathrm{O}_{\hat{o}} \mathrm{c}_{\hat{o}} \mathrm{R}_{\mathrm{t}+\hat{\mathrm{o}}}+\mathrm{d}_{1} \mathrm{E} / \mathrm{P}_{\mathrm{t}-1}+\mathrm{d}_{2} \mathrm{AG}_{\mathrm{t}}+\mathrm{z}_{\mathrm{t}}
$$

\footnotetext{
${ }^{3}$ In related papers, Warfield and Wild (1992) also examine the relation between current returns and future earnings, and Kothari and Shanken (1992) analyze the relation between aggregate stock returns and future dividends.
} 
Again as they predict, both the coefficients on the future earnings changes and the regression $\mathrm{R}^{2}$ rise when the future returns are added as regressors (for both models 3 and 4). In summary, CKSS's results indicate that earnings' lack of timeliness is the primary explanation for the low contemporaneous returnsearnings $\mathrm{R}^{2}$.

The key implication of CKSS's results for our tests is that the association between current returns and future earnings is correctly measured by $\mathrm{O}_{\hat{o}} \mathrm{~b}_{\hat{o}}$, the future ERC in (3) and (4), because the future ERC in (2) is downward biased due to the errors in variables problem. We compute the future ERC in models (3) and (4) to compare how informative current returns are about future earnings, across two groups of firms, those ranked high vs low on their FAF disclosure scores. Our (alternative) hypothesis is that greater disclosure produces a higher future ERC (i.e., greater price informativeness), ceteris paribus. To the best of our knowledge, this is the first study that compares informativeness of accounting signals by examining the information content of current returns for future earnings.

\subsection{Econometric Issues}

In estimating the future ERC's for the high and low disclosure groups from models (3) or (4), our tests might be sensitive to differential earnings timeliness between the groups, due to different

\footnotetext{
${ }^{4} \mathrm{CKSS}$ also point out that another potential explanation for the low contemporaneous returns-earnings $\mathrm{R}^{2}$ is value-irrelevant noise in earnings. Noise could be a problem for our tests if one group's earnings are noisier than the other's: the noisier group would have lower informativeness. We believe that nois e is not a problem for our tests due to both our matched industry pair design (described below), since firms in an industry tend to use similar accounting practices, and because CKSS reject noise as a primary explanation.
} 
accounting methods and/or business factors. That is, if the degree of disclosure is correlated with earnings timeliness, then our regression estimates might be inconsistent (because the regression error is correlated with disclosure). This is a potential example of the endogeneity problem: do firms with more timely earnings choose greater disclosure? If they do, and if we do not control for this, then the high disclosure group would have a higher future ERC not because of its enhanced disclosure, but because of its greater earnings timeliness.

In order to solve this potential endogeneity problem, we adopt the following procedures. First, we match high and low disclosers by industry. Since firms in an industry are homogenous in their real activities, by construction, and also use similar accounting methods (White, Sondhi, and Fried, 1998), their earnings should have similar timeliness and similar intrinsic forecastability (variability).

Second, Lang and Lundholm (1993) find that firms with higher disclosure scores are larger than firms with lower scores. Size might be an important omitted variable in models (3) and (4), since Freeman (1987), Collins, Kothari, and Rayburn (1987) and Collins and Kothari (1989) find that the returns of larger firms impound earnings news on a more timely basis than the returns of smaller firms (presumably due to larger firms' richer information environment). Since high disclosers are generally larger than low disclosers, size matching is infeasible, so we control for size by adding LVAL, the log of a firm's market value of equity, to the regression: ${ }^{5}$

$$
R_{t}=a+b_{0} \ddot{A} E_{t}+O_{\hat{o}} b_{\hat{o}} \ddot{A} E_{t+\hat{o}}+O_{\hat{o}} c_{\hat{o}} R_{t+\hat{o}}+d_{1} E / P_{t-1}+d_{2} A_{t}+d_{3} L V A L_{t}+z_{t}
$$

Note that the primary determinants of disclosure found by Lang and Lundholm (1993), size and

\footnotetext{
${ }^{5}$ Since enhanced disclosure lowers risk (Botosan, 1997, Welker, 1995), LVAL is also a risk control, as is E/P (Fama and French, 1992).
} 
both current and future performance, are all regressors in (5). Thus, we expect the regression residual to be orthogonal to disclosure, and our parameter estimates to be consistent.

Finally, we use as our earnings variable Earnings Before Interest, Taxes, Depreciation, and Amortization (EBITDA - Compustat annual data item \#13). Since EBITDA does not reflect these expenses, which are most vulnerable to differences in accounting measurement, and since it is not sensitive to differences in capital structure, it is more appropriate for our purposes than net income.

Following CKSS, we estimate regressions (1) thru (5) by deflating the earnings changes by the beginning of each year's earnings, $\mathrm{E}_{\mathrm{t}+\hat{\mathrm{o}}-1}$; thus, the earnings variables are single period growth rates.

\section{Disclosure Data Set and Sample}

Our sample is constructed from the AIMR-FAF disclosure scores over the period 1980-1993. As discussed in greater detail by Lang and Lundholm (1993, 1996), each year analysts rank firms by the informativeness of their disclosures. Firms are ranked within an industry, and scores are given for the following four disclosure categories: annual report, investor relations, other publications, and a total score (a weighted average of the three sub-categories).

Our sample is comprised of the non-bank firms in the AIMR rankings for the years 1980 through 1993 which exhibited consistent disclosure policies. We defined firms as having consistent disclosure policies if they appear in the same quartile in their AIMR industry ranking for two consecutive years. We selected firms with consistent disclosure policies, because the differential price informativeness of high vs low disclosure is most likely to be detectable when high or low disclosure is not a transitory phenomenon. Thus, using firms with consecutive high vs low ranking should increase the 
power of our tests. Banks were excluded because their accounting differs significantly from that of other sectors. Industries for which aggregate scores alone were assigned (without a breakdown for each of the three categories) were also excluded, since in our supplementary tests (Section 4.2) we use the subcategory scores. In addition, since the overwhelming majority of the rankings are broken down among the categories, imposing this condition did not cause us to lose many observations. Finally, industry reports that did not provide a ranking of the firms in their industry, but only assigned a rating of above average, average or below average were also excluded.

For our primary tests (Section 4.1), we used the total score as our disclosure variable, because it is the most comprehensive and thus best captures the theoretical construct we are trying to measure. In subsequent tests (Section 4.2) we use the specific disclosure categories. The AIMR committees tend to rate the larger firms in each industry because large firms tend to be more closely followed by analysts. Hence, the results presented in this study might not necessarily generalize to smaller firms.

Like Lang and Lundholm $(1993,1996)$ and most of the research using the FAF scores, we use the level of the disclosure score, rather than the change in the disclosure score like Healy, Hutton, and Palepu (1999). While a levels test is potentially vulnerable to correlated omitted variables (i.e., our results might not be due to differential disclosure, but to an omitted variable correlated with disclosure), we believe that a levels approach is appropriate for our tests for a number of reasons. First, matching firms by industry and year (and including size) controls for potential omitted variables, as described above. Second, since a firm's disclosure policy tends to be persistent, meaningful changes can take years, thus limiting the effective length of the time series and the power of the tests. Third, as Healy, Hutton, and Palepu point out, disclosure reductions are relatively rare. Finally, since changes in 
disclosure might themselves be correlated with other factors (such as good or bad news or other corporate policy changes), a changes approach is not a panacea. In fact, Healy, Hutton, and Palepu point out that significant disclosure changes often accompany major events such as restructurings. For all these reasons, we prefer the levels approach.

Certain characteristics of the FAF scores are important for our test methodology. First, the scores are calculated each year by industry-specific analyst committees, whose composition can change from year to year, and the scoring methods used by one industry-year committee are not necessarily comparable to the methods used by another committee. Thus, while we can unequivocally rank firms within an industry each year, we cannot unambiguously rank firms across industries in a given year or even across years within an industry. This is why virtually all researchers using the FAF data form percentile rankings of the firms within their industry grouping. Second, while a higher score within an industry-year group means greater disclosure (as judged by the analyst committee), there is no specific mapping between the scores and stock returns (or any other variable). Thus, Lang and Lundholm (1993) use rank correlations and rank regressions for their tests.

Our methodological approach reflects these features of the data. We use a matched pair design of high vs low disclosers (top vs bottom quartile) within each industry each year. As pointed out above, industry matching helps to control for the accounting and real business factors that affect both the inherent lead-lag relation between prices and earnings, and earnings' intrinsic forecastability (variability). We run pooled (or separate) OLS regressions for the two groups, with a dummy variable for high vs low. Thus, we do not use the actual disclosure scores, and we assume no specific functional form for the relation between disclosure score and future ERC. 
Table 1 provides a breakdown of the sample by industry and year. Since analyst coverage is expanding over time and not identical across industries, the number of observations is increasing slightly over time and is not equal across industries. However, due to our industry matching, the number of firms in each group (high and low disclosers) per industry-year is approximately equal. Although our sample is comprised of extreme disclosers (top and bottom quartile of their industry for at least two consecutive years), by construction the distribution of firms both across industries and over time is comparable to that of prior research using the FAF data.

Table 2 shows sample statistics for the 450 high discloser firm-years (Panel A) and the 371 low discloser firm-years (Panel B). ${ }^{6}$ Like Lang and Lundholm (1996), we find that high disclosers are larger, more profitable, and have higher stock returns than low disclosers.

The groups' differential performance is important, because Basu (1997) shows that due to the conservatism principle in accounting, bad news is impounded into earnings on a more timely basis than good news is. Since high disclosers are more successful firms, the relation between current returns and future earnings should be more timely for low disclosure firms. For a given finite horizon, this should bias down the future ERC of high disclosers relative to the future ERC of low disclosers, because the earnings of high disclosers might not yet reflect their good news. Thus, the differential timeliness of good news vs bad news firms works against our ability to find greater informativeness for high disclosers. Furthermore, Gelb (2000) finds that firms with high proprietary costs signal good news by dividends or stock repurchases, not more extensive voluntary disclosures. Thus, their stock prices should be

\footnotetext{
${ }^{6}$ The number of high and low disclosers are not exactly equal, because of our requirement that a firm be in the top or bottom quartile of its industry for two consecutive years. The greater number of high disclosers implies that high disclosers are slightly more persistent in their disclosure policy than low disclosers.
} 
relatively informative, even though they have low FAF scores. This, too, works against our ability to find greater informativeness for high disclosers.

\section{Empirical Results}

\subsection{Primary Tests}

Table 3 presents the primary empirical tests of regression models (3) and (5) for the two groups of high and low disclosers. Note that the results for both models are quite similar, so the inclusion of the control variables does not affect our inferences. For each disclosure group, we run pooled regressions with all firm-year observations. We do not run year-by-year regressions for our primary tests, because in some of the sample years, we have only about 20 observations in a group, and models (3) and (5) estimate eight and 11 parameters (including the intercept). ${ }^{7}$

While residual serial correlation is a potential problem in the pooled regressions, we believe that the problem is largely mitigated since many of the firms in the sample change from year to year.

However, to examine this issue, we estimated the correlation matrix of the annual series of residuals for each group. In fact, few of the pairwise correlations are significantly different from zero for either group, and the mean correlations between years $t$ and $t+1$ and between years $t$ and $t+2$ (estimates of the first and second order auto-correlations) are -.08 and .04 for the high disclosers and .08 and -.05 for the low disclosers, all of which are insignificantly different from zero. This indicates that residual auto-

\footnotetext{
${ }^{7}$ As a check on our results, we also estimated year-by-year regressions, and computed Fama-MacBeth (1973) t-statistics. The future ERC of the high disclosure group was greater than the future ERC of the low disclosure group for both models (3) and (5).
} 
correlation is not a problem in our regressions, and thus our reported significance levels are accurate. ${ }^{8}$

In estimating the models, we use each future year variable as an individual regressor (rather than adding them together), to maintain consistency with CKSS. However, in the interest of brevity, rather than show each coefficient, we report the sum of the coefficients on the future earnings changes and returns, and their associated 2-tailed significance levels for testing the null hypotheses $\mathrm{O}_{\hat{o}} \mathrm{~b}_{\hat{o}}=0$ and Ó$_{\hat{o}} \mathrm{c}_{\hat{\mathrm{o}}}=0$.

To test the statistical significance of the difference in future ERC's between the two groups, we run a pooled regression (high and low disclosers together) with both intercept and slope dummy variables. Although we are interested primarily in the coefficients on the future earnings changes, we allow all of the regression coefficients (not just those on the future earnings changes) to vary between the two groups in the pooled model. If the other coefficients differ between the two groups, but are constrained to be equal, any difference in future ERC's that we estimate might be due to the inappropriate restriction.

For example, although we do not test hypotheses about the current ERC, the current ERC of high disclosers might be different from that of low disclosers, since high disclosers tend to have good news, and Basu (1997) finds that good news firms have more persistent earnings and higher ERC's than

\footnotetext{
${ }^{8}$ The reported regressions are run after deleting outliers, defined as standardized residuals greater than or equal to three in absolute value, and influential observations, defined as Cook's Distance greater than or equal to one.

We also ran separate regressions with either LVAL or EP and AG, with similar results. In the interest of brevity, we only report the results with all three control variables.
} 
bad news firms. Alternatively, firms with more informative disclosures might have lower contemporaneous ERC's, because the information impounded in current earnings was impounded in stock prices of previous periods. In fact, Lang and Lundholm (1993) find that the returns-earnings correlation decreases with the level of disclosure. On the other hand, if the restrictions are appropriate, estimating additional parameters decreases the power of the test, which works against our ability to reject the null hypothesis of equal future ERC's between the two groups. Since the pooled model's results are redundant given the separate regressions, we only report the 2-tailed significance level for testing the null hypothesis of equal future ERC's.

Table 3 shows that the coefficients on the future returns are negative as expected, but as a group they are not significantly different from zero. ${ }^{9}$ The current ERC is significantly positive except for the expanded model (5) for the high disclosers. The coefficients on the control variables are of the expected sign and generally significant.

Of course, the coefficient of primary interest in Table 3 is the future ERC. The future ERC's of the high disclosers are .56 and .59, statistically significant at the .0001 level for models (3) and (5), respectively. For the low disclosers, the point estimates of the future ERC's are much lower (-.026 and $.005)$, and we cannot reject the null hypotheses that the future ERC is zero for both models. Moreover, the future ERC of the high disclosers is significantly greater than the future ERC of the low disclosers at the .0001 level for both models. ${ }^{10}$ These results indicate that stock prices of high disclosure firms have

\footnotetext{
${ }^{9}$ Some of the individual coefficients are significantly negative, even though the sum of the coefficients isn't.

${ }^{10}$ This result was obtained by estimating the pooled regression with intercept and slope dummy variables, as described previously.
} 
significantly greater forecasting power for future earnings than stock prices of low disclosure firms. To the best of our knowledge, this is the first direct evidence that enhanced disclosure is associated with stock prices more informative about future earnings.

As reported in Table 3, we also computed the statistical significance of the incremental $\mathrm{R}^{2}$ from model (1) to models (3) and (5) for each group (by testing the null hypothesis that all of the coefficients on the future earnings changes, future returns, and control variables jointly equal zero). The incremental $\mathrm{R}^{2}$ is significant for the high disclosers at the .0001 level for both models, but it is only significant for the low disclosers in the expanded model (5), and this is clearly due to the addition of the control variables. Thus, the incremental $\mathrm{R}^{2 \text { s }}$ provide additional evidence that enhanced disclosure makes stock prices more informative about future earnings.

\subsection{Additional Tests}

Our primary results are based on firms' composite disclosure scores and a three year forecasting horizon. We first investigate whether certain types of disclosure make stock prices more informative. The answer to this question is of interest to both research and practitioners. To address this question, we estimate model (3) where high and low disclosure is defined with respect to either the annual report score or the investor relations score. The results are shown in Table 4.

Table 4 shows that when disclosure is defined with respect to the annual report score, the future ERC is not significantly different from zero for either group. This suggests that enhanced annual report disclosures do not make stock prices more informative. Given that Lang and Lundholm (1996) find that the annual report and total scores are highly correlated, our results in Table 4 for the annual report score 
may seem surprising in light of our results for the total score in Table 3. However, recall that we define top quartile based on two consecutive years. Thus, consistent top quartile annual report firms (Table 4) are not necessarily top quartile total score firms (Table 3). In fact, 36\% (160/441) of the firms in the top quartile for two consecutive years based on the total score, are not in the top quartile based on the annual report score. Thus, the different composition of the sample firms appears to explain these results.

By contrast, when disclosure is defined with respect to the investor relations score, the future ERC of the high disclosers is significantly different from zero, while the future ERC of the low disclosers is not, and the difference in future ERC's between the groups is significant at the .0001 level. The results in Table 4 might reflect the fact that annual report disclosures are largely prescribed, so there is relatively little managerial discretion, whereas managers have much greater discretion in their investor relations disclosures. Thus, it is really not surprising that the investor relations score has a stronger relation with the future ERC.

Second, we examine whether our results are sensitive to the length of the forecasting horizon. Although we are careful to control for differential timeliness between the earnings of our two groups (see section 2.2), it might be the case that the earnings of high disclosure firms are more timely with respect to the three year horizon we use in Table 3 . That is, even if stock prices are equally informative about the entire series of future earnings for both groups, the earnings of the high disclosers might just recognize more of that information over the three year period. Recall, however, that the evidence in Basu (1997) implies that the earnings of the low disclosers should be more timely. Nevertheless, it is important to rule out differential timeliness as the explanation for our results.

To fully address this issue of course, we would need the entire future earnings series as 
explanatory variables in (3). While this is infeasible, we investigate the timeliness issue by using a 4 year horizon. If the higher future ERC's of high disclosure firms in Table 3 are due to their earnings having greater timeliness with respect to the three year horizon, then our results should weaken if we expand the horizon. Alternatively, if our results are due to greater stock price informativeness as we hypothesize, then high disclosure firms should still have a higher future ERC over the longer horizon.

The results are shown in Table 5. Using a 4 year horizon, our results are extremely similar to the results in Table 3: the future ERC's of the high disclosure group are significantly positive at the .0001 level, while the future ERC's of the low disclosure group are insignificantly different from zero. Furthermore, the future ERC's of the two groups are significantly different at the .0001 level, and the incremental $\mathrm{R}^{2}$ of the high disclosure group is significant, while that of the low disclosure group is not. Thus, the results in Table 5 indicate that our evidence that enhanced disclosure makes stock prices more informative is not due to differential timeliness between our groups, but to a genuine difference in informativeness.

\section{Conclusion}

In this paper, we examine the association between the degree of voluntary corporate disclosure and the informativeness of stock prices. We measure corporate disclosure using the AIMR-FAF annual corporate disclosure ratings. We define price informativeness by the association between current stock returns and future earnings changes: more informative stock price changes contain more information about future earnings changes. To measure this association, we use the multiple regression model of Collins, Kothari, Shanken, and Sloan (1994), wherein current returns are regressed against both current 
and future earnings changes and future stock returns. The aggregated coefficients on the future earnings changes, which we refer to as the future ERC, is our measure of infomativeness (association). By focussing on the benefits to the stock market, our research contrasts with most prior studies attempting to assess the benefits of enhanced corporate disclosure, which have focussed on benefits to the disclosing firm.

We hypothesize and find that greater disclosure is associated with greater price informativeness (i.e., higher future ERC). This is the first direct empirical evidence that enhanced disclosure results in stock prices that are more informative about future earnings, indicating that enhanced disclosure provides information benefits to the stock market.

In addition to measuring the benefits of enhanced voluntary disclosure, our methodology can be applied in other cases of interest to both academics and policymakers, such as assessing the benefits of additional required disclosures. 


\section{References}

Basu, Sadipto, 1997, "The Conservatism Principle and the Asymmetric Timeliness of Earnings", Journal of Accounting and Economics, 24, 3-37

Botosan, Christine A., 1997, "Disclosure Level and the Cost of Equity Capital", Accounting Review, 72, 323-349

Botosan, Christine A., and Marlene A. Plumlee, 1999, "Disclosure Level and the Cost of Equity Capital: An Examination of Analysts' Rankings of Corporate Disclosure”, working paper, University of Utah

Collins, Daniel W., S.P. Kothari, and Judy Rayburn, 1987, "Firm Size and the Information Content of Prices With Respect to Earnings", Journal of Accounting and Economics, 9, 111-138

Collins, Daniel W. and S.P. Kothari, 1989, “An Analysis of Intertemporal and Cross-Sectional Determinants of Earnings Response Coefficients, Journal of Accounting and Economics, $11,143-181$

Collins, Daniel W., S.P. Kothari, Jay Shanken, and Richard Sloan, 1994, "Lack of Timeliness and Noise as Explanations for the Low Contemporaneous Return-Earnings Association", Journal of Accounting and Economics, 18, 289-324

Fama, Eugene, 1970, "Efficient Capital Markets: A Review of Theory and Empirical Work", Journal of Finance

Fama, Eugene and James MacBeth, 1973, "Risk, return, and Equilibrium”, Journal of Political Economy,

Fama, Eugene and Ken French, 1992, "The Cross-Section of Expected Stock Returns", Journal of Finance, 427-465

Fishman, Michael J. And Kathleen M. Hagerty, 1989, "Disclosure Decisions by Firms and the Competition for Price Efficiency", The Journal of Finance, 44, 633-646

Freeman, Robert, 1987, "The Association Between Accounting Earnings and Security Returns for Large and small Firms", Journal of Accounting and Economics, 9, 195-228

Gelb, David, 1999, "Accounting Disclosures and Corporate Payout Policy: Special Dividends Versus Stock Repurchases”, Journal of Accounting, Auditing, and Finance, 14, 385-399 
Gelb, David, 2000, "Corporate Signaling With Dividends, Stock Repurchases, and Accounting Disclosures: An Empirical Study", Journal of Accounting, Auditing, and Finance, 15, 99120

Healy, Paul M., Amy P. Hutton, and Krishna G. Palepu, 1999, "Stock Performance and Intermediation Changes Surrounding Sustained Increases in Disclosure", Contemporary Accounting Research, 16, 485-520

Kothari, S.P. and Jay Shanken, 1992, "Stock Return Variation and Expected Dividends: A TimeSeries and Cross-Sectional Analysis", Journal of Financial Economics, 31, 177-210

Kothari, S.P. and Richard Sloan, 1992, "Information in Prices About Future Earnings: Implications for Earnings Response Coefficients", Journal of Accounting and Economics, $15,143-171$

Lang, Mark and Russell Lundholm, 1993, "Cross-Sectional Determinants of Analysts Ratings of Corporate Disclosures", Journal of Accounting Research, 31, 246-271

Lang, Mark and Russell Lundholm, 1996, "Corporate Disclosure Policy and Analyst Behavior", Accounting Review, 71, 467-492

Leuz, and R. Verrecchia, 2000, "The Economic Consequences of Increased Disclosure", working paper, Goethe University

Lev, Baruch, 1989, "On the Usefulness of Earnings: Lessons and Directions From Two Decades of Empirical Research", Journal of Accounting Research, Supplement, 153-192

Schipper, Katherine, 1995, "Academic Accounting Research and the Standard Setting Process", Accounting Horizons, 8, 61-73

Sengupta, Partha, 1998, "Corporate Disclosure Policy and the Cost of Debt", Accounting Review, $73,459-474$

Warfield, Terry D. and John J. Wild, 1992, "Accounting Recognition and the Relevance of Earnings as an Explanatory Variable for Returns", Accounting Review, 67, 821-842

Welker, M. 1995, "Disclosure Policy, Information Asymmetry, and Liquidity in Equity Markets", Contemporary Accounting Research, 11, 801-827

White, Gerald I., Ashwinpaul C. Sondhi, and Dov Fried, 1998, The Analysis and Use of Financial Statements, John Wiley and Sons 
Table 1

\section{Sample Composition}

Panel A: Composition of Sample by Industry $N=821$

$\begin{array}{ll}\text { Aerospace } & 27\end{array}$

$\begin{array}{ll}\text { Airline } & 20\end{array}$

Apparel $\quad 26$

Textiles $\quad 16$

Chemical $\quad 45$

Coal $\quad 3$

$\begin{array}{lr}\text { Construction } & 10\end{array}$

$\begin{array}{lr}\text { Container } & 7\end{array}$

Diversified Companies $\quad 13$

Electrical Equipment $\quad 36$

Financial Services $\quad 23$

Food $\quad 38$

$\begin{array}{ll}\text { Health Care and Services } & 67\end{array}$

Machinery $\quad 52$

$\begin{array}{ll}\text { Natural Gas } & 58\end{array}$

Metals $\quad 12$

$\begin{array}{ll}\text { Petroleum } & 74\end{array}$

Paper $\quad 24$

$\begin{array}{ll}\text { Publishing / Media } & 70\end{array}$

$\begin{array}{ll}\text { Railroad } & 40\end{array}$

$\begin{array}{ll}\text { Retail } & 104\end{array}$

$\begin{array}{lc}\text { Specialty Chemicals } & 56\end{array}$

Panel B: Composition of Sample by Year $N=821$

1981

56

1982

51

1983

61

1984

57

1985

47

1986

48

1987

56

1988

68

1989

74

1990

78

1991

83

1992

75

1993

67 
Table 2

Descriptive Statistics for the Sample Firms.

\begin{tabular}{|c|c|c|c|c|}
\hline & Mean & $\begin{array}{l}\text { Quartile } \\
\text { One }\end{array}$ & Median & $\begin{array}{l}\text { Quartile } \\
\text { Three }\end{array}$ \\
\hline \multicolumn{5}{|c|}{$\begin{array}{l}\text { Panel A: Firms appearing in the top quartile of their AIMR industry grouping during the past two } \\
\text { years }(N=450)\end{array}$} \\
\hline Market Capitalization ${ }^{1 *}$,\# & 5602 & 1297 & 2519 & 5332 \\
\hline Disclosure Rating ${ }^{2 *}, \#$ & .870 & .830 & 0.88 & 0.92 \\
\hline Profitability $^{3 *}$ & .191 & .143 & .184 & .237 \\
\hline Stock Price Change ${ }^{4}{ }^{*}, \#$ & .194 & -.001 & .171 & .356 \\
\hline Earnings Price Ratio ${ }^{5}$ \# & .065 & .046 & .064 & 0.088 \\
\hline
\end{tabular}

Panel B: Firms appearing in the bottom quartile of their AIMR industry grouping during the past two years $(N=371)$

\begin{tabular}{|lcccc||}
\hline Market Capitalization & 3688 & 588 & 1459 & 3829 \\
Disclosure Rating & .137 & 0.08 & .130 & 0.180 \\
Profitability & .187 & .121 & .168 & .235 \\
Stock Price Change & .145 & -0.036 & .096 & .320 \\
Earnings Price Ratio & .048 & .044 & .067 & .088 \\
\hline
\end{tabular}

* Denotes significance of the Wilcoxon Z statistic at the 5\% significance level for the difference between the high and low disclosers.

\# Denotes significance of the t-test at the 5\% significance level for the difference between the high and low disclosers.

${ }^{1}$ Total market capitalization measured as of the beginning of the current fiscal year.

${ }^{2}$ Percentile disclosure rating of the firm in its AIMR industry group for the current year. The ratings measure the level of information provided by the firm in its annual report, quarterly reports and other publications and its investor relations. The aggregate rating is a weighted average of the scores received in the three categories.

${ }^{3}$ Current year operating income before depreciation and taxes, scaled by total assets.

${ }^{4}$ The change in stock price (measured over the current fiscal year) plus the dividend per share, scaled by the stock price as of the end of the past fiscal year.

${ }^{5}$ The earnings-price ratio, calculated as of the close of the fiscal year. 
Table 3

Results of OLS Regression Tests of the Effect of

Firms' Disclosures on the Relationship Between Current Stock Price

Changes and Future Earnings Changes.

\begin{tabular}{|c|c|c|c|c|}
\hline \multirow{3}{*}{$\begin{array}{l}\text { Independent } \\
\text { Variables }^{\mathrm{a}} \\
\\
\text { Intercept }\end{array}$} & \multicolumn{4}{|c|}{ Dependent Variable: Current Price Change } \\
\hline & \multicolumn{2}{|c|}{$\begin{array}{l}\text { Firms appearing in the top quartile } \\
\text { of their AIMR ratings for the past } \\
\text { two years. }\end{array}$} & \multicolumn{2}{|c|}{$\begin{array}{l}\text { Firms appearing in the bottom } \\
\text { quartile of their AIMR ratings for the } \\
\text { past two years. }\end{array}$} \\
\hline & $\begin{array}{l}.139 \\
(.001)\end{array}$ & $\begin{array}{c}.403 \\
(.001)\end{array}$ & $\begin{array}{l}.131 \\
(.001)\end{array}$ & $\begin{array}{l}.214 \\
(.021)\end{array}$ \\
\hline $\mathrm{ERC}^{1}$ & $\begin{array}{l}.113 \\
(.002)\end{array}$ & $\begin{array}{l}0.031 \\
(.317)\end{array}$ & $\begin{array}{c}.075 \\
(.001)\end{array}$ & $\begin{array}{l}.079 \\
(.001)\end{array}$ \\
\hline Future ERC ${ }^{2}$ & $\begin{array}{c}.563 \\
(.001)\end{array}$ & $\begin{array}{c}.593 \\
(.001)\end{array}$ & $\begin{array}{l}-.026 \\
(.567)\end{array}$ & $\begin{array}{c}.005 \\
(.903)\end{array}$ \\
\hline Future Price Change $^{3}$ & $\begin{array}{l}-.037 \\
(.660)\end{array}$ & $\begin{array}{l}-.037 \\
(.675)\end{array}$ & $\begin{array}{l}-.033 \\
(.746)\end{array}$ & $\begin{array}{l}-.053 \\
(.593)\end{array}$ \\
\hline Earnings-Price Ratio ${ }^{4}$ & & $\begin{array}{c}.141 \\
(.630)\end{array}$ & & $\begin{array}{c}.602 \\
(.001)\end{array}$ \\
\hline Asset Growth ${ }^{5}$ & & $\begin{array}{c}.157 \\
(.022)\end{array}$ & & $\begin{array}{l}.126 \\
(.034)\end{array}$ \\
\hline Market Capitalization ${ }^{6}$ & & $\begin{array}{l}-.036 \\
(.001)\end{array}$ & & $\begin{array}{l}-.018 \\
(.131)\end{array}$ \\
\hline Observations & 441 & 441 & 365 & 364 \\
\hline $\mathrm{R}^{2}$ & .167 & .196 & .043 & .110 \\
\hline $\begin{array}{l}\text { Increase in } \mathrm{R}^{2} \text { from the } \\
\text { ERC base } \text { model }^{7}\end{array}$ & $\begin{array}{c}.148 \\
(.001)\end{array}$ & $\begin{array}{c}.177 \\
(.001)\end{array}$ & $\begin{array}{c}.011 \\
(.452)\end{array}$ & $\begin{array}{c}.078 \\
(.001)\end{array}$ \\
\hline
\end{tabular}

${ }^{a}$ The estimated coefficients and two-tailed p-values (reported in the parenthesis).

${ }^{1}$ The earnings-response coefficient for the current fiscal year.

${ }^{2}$ The sum of the earnings-response coefficients for the following three fiscal years. 
${ }^{3}$ The sum of the coefficients of the stock price changes for the following three fiscal years. The change in stock price for each year is measured by the change in the stock price over the year plus the dividend per share during the fiscal year, scaled by the stock price as of the end of past fiscal year.

${ }^{4}$ The earnings-price ratio, calculated as of the close of the fiscal year.

${ }^{5}$ The increase in the firm's assets over the current fiscal year, scaled by the assets as of the beginning of the fiscal year.

${ }^{6}$ The natural logarithm of the total market capitalization measured as of the beginning of the current fiscal year.

${ }^{7}$ The increase in the R-square from the model using only the current earnings change as an independent variable (referred to as the base model). The R-square for the high (low) disclosures group in the base model is .019 (.032). The p-value for the significance level of the increase in R-square appears in the parentheses. 
Table 4

Results of OLS Regression Tests of the Effect of Firms' Annual Report and Investor Relations Disclosures

on the Relationship Between Current Stock Price

Changes and Future Earnings Changes.

\begin{tabular}{|c|c|c|c|c|}
\hline \multirow{3}{*}{$\begin{array}{l}\text { Independent } \\
\text { Variables }^{\mathrm{a}}\end{array}$} & \multicolumn{4}{|c|}{ Dependent Variable: Current Price Change } \\
\hline & \multicolumn{2}{|c|}{$\begin{array}{l}\text { Firms appearing in the top quartile } \\
\text { of their AIMR annual } \\
\text { report/investor relations ratings for } \\
\text { the past two years. }\end{array}$} & \multicolumn{2}{|c|}{$\begin{array}{l}\text { Firms appearing in the bottom } \\
\text { quartile of their AIMR annual } \\
\text { report/investor relations ratings for } \\
\text { the past two years. }\end{array}$} \\
\hline & $\begin{array}{c}\text { Annual Report } \\
\text { Disclosures } \\
\end{array}$ & $\begin{array}{l}\text { Investor } \\
\text { Relations }\end{array}$ & $\begin{array}{c}\text { Annual Report } \\
\text { Disclosures } \\
\end{array}$ & $\begin{array}{l}\text { Investor } \\
\text { Relations }\end{array}$ \\
\hline Intercept & $\begin{array}{c}.131 \\
(.001)\end{array}$ & $\begin{array}{c}.151 \\
(.001)\end{array}$ & $\begin{array}{c}.161 \\
(.001)\end{array}$ & $\begin{array}{c}.151 \\
(.001)\end{array}$ \\
\hline $\mathrm{ERC}^{1}$ & $\begin{array}{l}.121 \\
(.002)\end{array}$ & $\begin{array}{l}0.086 \\
(.019)\end{array}$ & $\begin{array}{c}.066 \\
(.001)\end{array}$ & $\begin{array}{l}.061 \\
(.007)\end{array}$ \\
\hline Future ERC ${ }^{2}$ & $\begin{array}{l}.009 \\
(.901)\end{array}$ & $\begin{array}{c}.427 \\
(.001)\end{array}$ & $\begin{array}{l}-.012 \\
(.856)\end{array}$ & $\begin{array}{l}-.016 \\
(.727)\end{array}$ \\
\hline Future Price Change ${ }^{3}$ & $\begin{array}{c}.089 \\
(.324)\end{array}$ & $\begin{array}{l}-.102 \\
(.265)\end{array}$ & $\begin{array}{l}-.225 \\
(.027)\end{array}$ & $\begin{array}{l}-.162 \\
(.099)\end{array}$ \\
\hline Observations & 389 & 389 & 330 & 323 \\
\hline $\mathrm{R}^{2}$ & .071 & .122 & .076 & .052 \\
\hline $\begin{array}{l}\text { Increase in } \mathrm{R}^{2} \text { from the } \\
\text { ERC base } \text { model }^{4}\end{array}$ & $\begin{array}{c}.038 \\
(.004)\end{array}$ & $\begin{array}{l}.117 \\
(.001)\end{array}$ & $\begin{array}{c}.022 \\
(.259)\end{array}$ & $\begin{array}{l}-.035 \\
(.189)\end{array}$ \\
\hline
\end{tabular}

${ }^{a}$ The estimated coefficients and two-tailed p-values (reported in the parenthesis).

${ }^{1}$ The earnings-response coefficient for the current fiscal year.

${ }^{2}$ The sum of the earnings-response coefficients for the following three fiscal years.

${ }^{3}$ The sum of the coefficients of the stock price changes for the following three fiscal years. The change in stock price for each year is measured by the change in the stock price over the year plus the dividend per share during the fiscal year, scaled by the stock price as of the end of past fiscal year.

${ }^{4}$ The increase in the R-square from the model using only the current earnings change as an independent variable (referred to as the base model). The R-square for the high (low) disclosures group in the base model for the annual report ratings regression is .033 (.054). The R-square for the high (low) disclosures group in the base model for the investor relations ratings regression is .005 (.087) The p-value for the significance level of the increase in R-square appears in the parentheses. 
Table 5

Results of OLS Regression Tests of the Effect of

Firms' Disclosures on the Relationship Between Current Stock Price

Changes and Future Earnings Changes, Measured Over a Four Year Horizon.

\begin{tabular}{|c|c|c|c|c|}
\hline \multirow{3}{*}{$\begin{array}{l}\text { Independent } \\
\text { Variables }^{\mathrm{a}} \\
\\
\text { Intercept }\end{array}$} & \multicolumn{4}{|c|}{ Dependent Variable: Current Price Change } \\
\hline & \multicolumn{2}{|c|}{$\begin{array}{l}\text { Firms appearing in the top quartile } \\
\text { of their AIMR ratings for the past } \\
\text { two years. }\end{array}$} & \multicolumn{2}{|c|}{$\begin{array}{l}\text { Firms appearing in the bottom } \\
\text { quartile of their AIMR ratings for the } \\
\text { past two years. }\end{array}$} \\
\hline & $\begin{array}{c}.136 \\
(.001)\end{array}$ & $\begin{array}{c}.396 \\
(.001)\end{array}$ & $\begin{array}{c}.116 \\
(.001)\end{array}$ & $\begin{array}{l}.119 \\
(.205)\end{array}$ \\
\hline $\mathrm{ERC}^{1}$ & $\begin{array}{l}.118 \\
(.001)\end{array}$ & $\begin{array}{l}.028 \\
(.373)\end{array}$ & $\begin{array}{l}.075 \\
(.001)\end{array}$ & $\begin{array}{l}.070 \\
(.004)\end{array}$ \\
\hline Future ERC ${ }^{2}$ & $\begin{array}{c}.723 \\
(.001)\end{array}$ & $\begin{array}{c}.861 \\
(.001)\end{array}$ & $\begin{array}{l}-.025 \\
(.712)\end{array}$ & $\begin{array}{l}.024 \\
(.722)\end{array}$ \\
\hline Future Price Change $^{3}$ & $\begin{array}{l}-.093 \\
(.395)\end{array}$ & $\begin{array}{l}-.169 \\
(.131)\end{array}$ & $\begin{array}{c}.034 \\
(.771)\end{array}$ & $\begin{array}{l}-.009 \\
(.939)\end{array}$ \\
\hline Earnings-Price Ratio ${ }^{4}$ & & $\begin{array}{l}.404 \\
(.186)\end{array}$ & & $\begin{array}{l}.836 \\
(.001)\end{array}$ \\
\hline Asset Growth ${ }^{5}$ & & $\begin{array}{l}.177 \\
(.011)\end{array}$ & & $\begin{array}{l}.114 \\
(.052)\end{array}$ \\
\hline Market Capitalization ${ }^{6}$ & & $\begin{array}{l}-.037 \\
(.001)\end{array}$ & & $\begin{array}{l}-.008 \\
(.486)\end{array}$ \\
\hline Observations & 432 & 432 & 349 & 347 \\
\hline $\mathrm{R}^{2}$ & .177 & .224 & .045 & .123 \\
\hline $\begin{array}{l}\text { Increase in } \mathrm{R}^{2} \text { from the } \\
\text { ERC base } \text { model }^{7}\end{array}$ & $\begin{array}{l}.158 \\
(.001)\end{array}$ & $\begin{array}{c}.205 \\
(.001)\end{array}$ & $\begin{array}{c}.013 \\
(.591)\end{array}$ & $\begin{array}{c}.091 \\
(.001)\end{array}$ \\
\hline
\end{tabular}

a The estimated coefficients and two-tailed p-values (reported in the parenthesis).

${ }^{1}$ The earnings-response coefficient for the current fiscal year.

${ }^{2}$ The sum of the earnings-response coefficients for the following four fiscal years. 
${ }^{3}$ The sum of the coefficients of the stock price changes for the following four fiscal years. The change in stock price for each year is measured by the change in the stock price over the year plus the dividend per share during the fiscal year, scaled by the stock price as of the end of past fiscal year.

${ }^{4}$ The earnings-price ratio, calculated as of the close of the fiscal year.

${ }^{5}$ The increase in the firm's assets over the current fiscal year, scaled by the assets as of the beginning of the fiscal year.

${ }^{6}$ The natural logarithm of the total market capitalization measured as of the beginning of the current fiscal year.

${ }^{7}$ The increase in the R-square from the model using only the current earnings change as an independent variable (referred to as the base model). The R-square for the high (low) disclosures group in the base model is .019 (.032). The p-value for the significance level of the increase in R-square appears in the parentheses. 